\title{
Current placenta previa management and outcome in a rural tertiary care centre
}

\section{Reena Sood*, Swati Sharma, Madhu Nagpal, Madhurima Arora}

Department of Obstetrics and Gynecology, Sri Guru Ram Das Institute of Medical Sciences and Research, Sri Amritsar, Punjab, India

Received: 05 April 2017

Revised: 11 April 2017

Accepted: 17 April 2017

\section{*Correspondence:}

Dr. Reena Sood,

E-mail: dr.reenasood@gmail.com

Copyright: ( $)$ the author(s), publisher and licensee Medip Academy. This is an open-access article distributed under the terms of the Creative Commons Attribution Non-Commercial License, which permits unrestricted non-commercial use, distribution, and reproduction in any medium, provided the original work is properly cited.

\section{ABSTRACT}

Background: The reported incidence for placenta previa averages $0.3 \%$ or 1 case in 300 to 400 deliveries. Multiparity, advanced maternal age, cigarette smoking, previous caesarean delivery, history of abortions or uterine surgical procedures are some of the risk factors contributing to the development of placenta previa. Massive obstetrical haemorrhage in placenta previa is associated with severe maternal morbidity and mortality. A significant number of mothers can be saved if right approach of management is followed in placenta previa.

Methods: The present case study is a retrospective analysis carried out in a tertiary care centre to study the risk factors and maternal and perinatal outcome in cases of placenta previa. The study included antenatal patients diagnosed as placenta previa on sonography at or $>26$ weeks of pregnancy. Data was compiled and statistically analysed.

Results: Incidence of Placenta Previa in our study was $0.54 \% .73 .2 \%$ patients had history of previous cesarean sections. $53.6 \%$ patients were referred from outside. $98.2 \%$ patients delivered by caesarean section. Obstetric hysterectomy was required in $3.5 \%$ of total cases. $10.7 \%$ cases required the ICU admission after delivery. There was no maternal mortality in the study group. The mean gestational age at delivery was $35 \pm 2.4$ weeks. The mean APGAR at 5 min was $9 \pm 2.2$.

Conclusions: Increasing rates of caesarean sections in present era indicate that incidence of Placenta Previa is expected to rise. Good antenatal care, availability of emergency obstetric services, infrastructure, blood bank facility, HDU and ICU care and NICU services can improve maternal and neonatal outcome.

Keywords: Cesarean section Placenta previa, Placenta accreta

\section{INTRODUCTION}

Obstetric haemorrhage is the most important cause of maternal morbidity in the developing world. ${ }^{1}$ Placenta previa exists when the placenta is inserted wholly or in part into the lower segment of the uterus. Reported incidence of placenta previa averages $0.3 \%$ or 1 case in 300 to 400 deliveries. $^{2}$ Multiparity, advanced maternal age, cigarette smoking, previous caesarean delivery, history of abortions or uterine surgical procedures are some of the risk factors contributing to the development of placenta previa. ${ }^{3-7}$

Massive obstetrical haemorrhage in placenta previa is associated with severe maternal morbidity and mortality. In a report of Registrar General India, haemorrhage accounts for $38 \%$ amongst all causes of maternal deaths. ${ }^{8}$ Studies have shown that placenta previa carries greater risks of surgical complications including obstetric hysterectomy and massive haemorrhage requiring blood transfusion. ${ }^{9}$ 
A significant number of mothers can be saved if right approach of management is followed in placenta previa. With the rising incidence of caesarean section combined with increasing maternal age, the number of cases of placenta previa and its complications, including placenta accreta is expected to increase. ${ }^{10,11}$ Prematurity has been reported as a consistent finding in the cases of placenta previa in many studies. ${ }^{11-15}$

\section{Aims and objectives}

1. To study risk factors of placenta previa

2. To study maternal and perinatal outcome in cases of placenta previa

3. To audit Placenta Previa management in view of rising trends of repeat cesarean section morbid adhesions.

\section{METHODS}

The present case study is a retrospective analysis carried out in SGRDIMSAR from $1^{\text {st }}$ Jan 2014 to $31^{\text {st }}$ Dec 2016. Our Institution is a tertiary care centre situated in rural area in the periphery of Amritsar. The study included antenatal patients diagnosed as placenta previa on sonography at or $>26$ weeks of pregnancy. All patients included had delivery in our institution. After taking approval from institution ethics committee, data was retrieved by reviewing obstetric admission register, operative register and case records.

Each case record was analysed in detail with special emphasis on maternal profile, clinical presentation, surgical procedure done, complications, if any and neonatal status. Parameters studied were sociodemographic profile, risk factors, type of placenta previa, anaemia, interventional procedures done, number of blood transfusions required, ICU stay for mother. Parameters studied for neonatal outcome were gestational age at delivery and APGAR score of the neonate. Preterm births were subcategorised according to WHO classification into extremely preterm ( $<28$ weeks), very preterm ( 28 to $<32$ weeks), moderate to late preterm (32 to <37 weeks) Data was compiled and statistically analysed for audit purpose. Data analysis was done using SPSS version 20.0. The multinomial regression model was used to assess the association of type of placenta previa, as a dependant variable with APGAR score at 5 mins. Chi square test was used to assess the association of gestational age at birth with the type of placenta previa. $P$ value $<0.05$ was taken as statistically significant.

\section{Inclusion criteria}

Patient with sonographic report showing singleton pregnancy and abnormal placental attachment as low lying placenta, placenta previa or placenta accreta at or after 26 weeks of gestation.

\section{Exclusion criteria}

Exclusion criteria of the study was multiple pregnancies, APH due to any other cause.

\section{RESULTS}

During the 3-year period study, the total number of deliveries was 10432 . Of these 56 were singleton pregnancies with $\mathrm{PP}$, resulting in an incidence of PP of $0.54 \%$.

Out of these, there were $9(16.1 \%)$ patients with type I Placenta previa, $15(26.8 \%)$ patients with type II or marginal placenta previa, $17(30.4 \%)$ patients with type III incomplete placenta previa and $13(23.2 \%)$ patients with type IV or complete placenta previa diagnosed antenatally on the ultrasonography. 2 patients $(3.6 \%)$ were diagnosed with placenta accreta on sonography during the antenatal period. in both cases colour doppler was done and findings were suggestive of placenta accreta. Both these cases had history of previous caesarean sections.

Table 1: The incidence, demographic profile and risk factors for Placenta previa.

\begin{tabular}{|c|c|c|c|}
\hline Parameter & & $\begin{array}{l}\text { No. of } \\
\text { patients }\end{array}$ & $\%$ \\
\hline \multirow{3}{*}{ Age (yrs) } & $<20$ & 3 & 5 \\
\hline & $21-30$ & 35 & 61.4 \\
\hline & $31-40$ & 18 & 31.6 \\
\hline \multirow{3}{*}{ Parity } & $0-1$ & 12 & 21.4 \\
\hline & $2-4$ & 38 & 67.9 \\
\hline & $>=5$ & 6 & 10.7 \\
\hline \multirow{3}{*}{$\begin{array}{l}\text { Registration } \\
\text { status }\end{array}$} & Booked & 25 & 44.6 \\
\hline & Unbooked & 1 & 1.8 \\
\hline & Referred & 30 & 53.6 \\
\hline \multirow{5}{*}{$\begin{array}{l}\text { Type of } \\
\text { placenta }\end{array}$} & I & 9 & 16.1 \\
\hline & II & 15 & 26.8 \\
\hline & III & 17 & 30.4 \\
\hline & IV & 13 & 23.2 \\
\hline & Placenta Accreta & 2 & 3.6 \\
\hline \multirow{4}{*}{$\begin{array}{l}\text { Obstetric } \\
\text { history }\end{array}$} & Previous 1 LSCS & 12 & 21.1 \\
\hline & Previous 2 LSCS & 27 & 47.4 \\
\hline & $\begin{array}{l}\text { Previous }>2 \\
\text { LSCS }\end{array}$ & 2 & 3.5 \\
\hline & $\begin{array}{l}\text { Previous } \\
\text { Curettage }\end{array}$ & 15 & 26.7 \\
\hline \multirow{3}{*}{ Anemia } & $\begin{array}{l}\text { Mild (10-10.9 } \\
\mathrm{g} / \mathrm{dl})\end{array}$ & 19 & 33.9 \\
\hline & $\begin{array}{l}\text { Moderate (7- } \\
9.9 \mathrm{~g} / \mathrm{dl})\end{array}$ & 22 & 39.3 \\
\hline & Severe $(<7 \mathrm{~g} / \mathrm{dl})$ & 3 & 5.4 \\
\hline
\end{tabular}

The maximum number of patients in the study group belonged to the age group 20-35 years and the mean maternal age for the development of placenta previa was $27.9 \pm 4.4$ yrs. 
None of the patients in our study had a history of smoking.

Being a tertiary care institute, $30(53.6 \%)$ patients were referred to us for safe confinement. 25 (44.6\%) cases were booked in our institute. Only $1(1.8 \%)$ patient was admitted unregistered and undiagnosed.

Out of the 56 women, $12(21.4 \%)$ belonged to the nulliparous/ primiparous group. $44(78.6 \%)$ patients were multipara.

41patients had history of previous caesarean section accounting to $73.2 \% .12$ out of 56 patients had history of previous $1 \mathrm{LSCS}$ which accounted to $21.4 \% .27$ women had previous 2 LSCS which accounted for $47.4 \%$. Two women $3.5 \%$ had history of $>2$ previous LSCS.

15 cases had history of both previous curettage and caesarean section accounting to $26.7 \% 1$ case $(1.78 \%)$ had previous vaginal delivery (unscarred uterus).

Mild anaemia at the time of admission was found in 19 cases which accounted to $33.9 \%$ amongst the total patients, moderate anaemia was found in 22 patients accounting to $39.2 \%$, severe anaemia was found in 3 cases which accounted to $5.4 \%$. Only 12 (21.4\%) patients had $\mathrm{Hb}>11 \mathrm{gm}$ at the time of admission. All these patients were booked cases, getting regular antenatal check-ups.

Malpresentations at the time of delivery were seen in 21 cases $(37.5 \%)$.

Duration of Pre-operative stay in hospital in diagnosed cases during conservative management ranged from 1-31 days.

Out of the 56 women with placenta previa, 55 were patients delivered by caesarean section making it to $98.2 \%$. Only $1(1.78 \%)$ patient with type I placenta previa at gestational age $27 \mathrm{wks} 5$ days delivered vaginally. In the caesarean section group, $27(48.2 \%)$ patients had an emergency surgery and $29(51.8 \%)$ patients had an elective caesarean section. Out of the 56 patients, $4(7.14 \%)$ patients presented with heavy bout of bleeding with shock.

Intraoperatively, B lynch suturing was required in 2 cases which accounted to $3.5 \%$ of the total cases. Uterine artery ligation was required in 4 cases accounting for $7.1 \%$ of the total cases. Internal artery ligation was required in 1 patient $(1.78 \%)$ of the total cases. Obstetric hysterectomy was required in 2 out of the total 56 women at time of cesarean section which accounted to $3.5 \%$. Both cases were pre operatively diagnosed as placenta accreta. Relaparotomy followed by hysterectomy for PPH was required in 1 case accounting to $1.78 \%$ of the total cases. No case of bladder, ureteric or bowel injury was there in study period.
Blood and blood components were required in 30 patients accounting to $53.5 \%$. Requirement of PRBCs ranged from $1-5$ units. 2 patients $(3.57 \%)$ required transfusion of FFPs. The remaining $26(46.4 \%)$ patients did not require blood or its components. Only 6 out of 56 patients were admitted to the ICU after delivery accounting to 10.7\%. 52(89.3\%) patients did not require ICU admissions and were managed in the obstetric wards.

Fortunately, there was no maternal mortality in the study group. No case of post-operative sepsis, DIC, renal failure occurred in the study period. ICU stay in shifted patients ranged from 1-3 days only. No case of nosocomial infection was found.

Table 2: Distribution of gestational age at birth.

\begin{tabular}{|lll|}
\hline $\begin{array}{l}\text { Mean gestational age at delivery (in } \\
\text { weeks) }\end{array}$ & No. & $\%$ \\
\hline Extremely Preterm (<28 weeks) & 1 & 1.8 \\
\hline Very Preterm (28-32 weeks) & 5 & 8.8 \\
\hline Moderate to late preterm (32-37 weeks) & 41 & 73.2 \\
\hline Early Term (37-38 weeks) & 8 & 14.2 \\
\hline Full Term (>39 weeks) & 1 & 1.8 \\
\hline
\end{tabular}

The mean gestational age at delivery was $35+/-2.4$ wks weeks ranging from 27.5 wks-39 wks (Table 2). No differences in the gestational age at delivery were observed for the different types of placenta previa when Chi square test was applied ( $\mathrm{p}$ value $=0.2$ nonsignificant) (Table 3).

Table 3: Association of gestation of newborns with type of placenta previa.

\begin{tabular}{|lcccc|}
\hline $\begin{array}{l}\text { Gestational age at } \\
\text { delivery }\end{array}$ & I & II & III & IV \\
\hline $\begin{array}{l}\text { Extremely preterm }(<28 \\
\text { weeks })\end{array}$ & 1 & 0 & 0 & 0 \\
\hline $\begin{array}{l}\text { Very preterm }(28-32 \\
\text { weeks })\end{array}$ & 0 & 3 & 0 & 2 \\
\hline $\begin{array}{l}\text { Moderate to Late preterm } \\
\text { (32-37 weeks) }\end{array}$ & 6 & 10 & 15 & 10 \\
\hline $\begin{array}{l}\text { Early term }\left(37^{0 / 7}-38^{6-7 w k s}\right) \\
\text { Full term }>39 \text { wks }\end{array}$ & 0 & 2 & 2 & 2 \\
\hline Chi -square $=13.906 ; \mathrm{df}=12 ; \mathrm{p}=0.307$ & 0 & 1 \\
\hline
\end{tabular}

The mean APGAR at 1 min was $8+/-2.02$. The mean APGAR at 5 min was $9 \pm 2.2$. Out of 56 neonates, 2 could not be revived. Multinomial logistic regression analysis revealed no significant association between the APGAR and the placental location (Table 4).

The reference category was type IV placenta previa. The multinomial logistic regression analysis revealed no significant results between APGAR score at 5 mins with the placental location. 
Table 4: Multinomial regression analysis between APGAR score at 5 minutes with type of placenta previa.

\begin{tabular}{|c|c|c|c|c|}
\hline & & $\begin{array}{l}\text { Adjusted } \\
\text { ODDS ratio }\end{array}$ & $\begin{array}{l}\text { CI } \\
(95 \%)\end{array}$ & P value \\
\hline \multirow{3}{*}{$\begin{array}{l}\text { APGAR } \\
\text { at } 5 \\
\text { mins }\end{array}$} & $\begin{array}{l}\text { Type I } \\
\text { PP }\end{array}$ & 0.722 & $\begin{array}{l}0.465- \\
1.12\end{array}$ & 0.146 \\
\hline & $\begin{array}{l}\text { Type II } \\
\text { PP }\end{array}$ & 0.715 & $\begin{array}{l}0.474- \\
1.07\end{array}$ & 0.110 \\
\hline & $\begin{array}{l}\text { Type } \\
\text { III PP }\end{array}$ & 0.850 & $\begin{array}{l}0.556- \\
1.30\end{array}$ & 0.454 \\
\hline
\end{tabular}

\section{DISCUSSION}

Varying incidences have been reported in literature. One study reports incidence as $0.4-0.5 \%$, another study reports incidence as $1.9 \% .13,16$

In our study, out of the 56 women $78.6 \%$ patients were multiparae. This is consistent with earlier studies where multiparity is reported as a risk factor. ${ }^{3-6,13}$

In our study 41patients had history of previous cesarean sections accounting to $73.2 \%$. Previous cesarean section has been reported as the most common risk factor for Placenta Previa in earlier studies also., $, 5,13,16$

RCOG guidelines recommend that Women with a previous caesarean section require a higher index of suspicion as there are two problems to be excluded: placenta praevia and placenta accreta. If the placenta lies anteriorly and reaches the cervical os at 20 weeks, a follow-up scan can help identify if it is implanted into the caesarean section scar. ${ }^{17}$

Smoking has been reported as a risk factor for Placenta Previa in earlier studies. ${ }^{5,6,16}$ But none of the patients in our study had a history of smoking. This can be because of different demographic profile and behaviour of different populations.

Being a tertiary care institute, $30(53.6 \%)$ patients were referred from outside and $25(44.6 \%)$ cases were booked in our institute. Only $1(1.8 \%)$ patient was admitted unregistered and undiagnosed. This can be attributed to better utilisation of health services in present days. Availability of free 108 ambulance service helps people from remote areas to reach hospitals timely.

Only 4 patients $(7.14 \%)$ presented to us in a condition of shock (shock index >0.7). Rest were haemodynamically stable at time of admission.

Severe anaemia $(<7 \mathrm{~g} / \mathrm{dl} \mathrm{Hb})$ was found in 3 cases which accounted to $5.4 \%$. Only $12(21.4 \%)$ patients had $\mathrm{Hb}>$ $11 \mathrm{gm}$ at the time of admission. All these patients were booked cases, getting regular antenatal check-ups. This further emphasises the importance of regular antenatal care and iron supplementation.
Out of the 56 women with placenta previa, 55 patients were delivered by caesarean section making it to $98.2 \%$. Only $1(1.78 \%)$ patient with type I placenta previa at gestational age $27 \mathrm{wks} 5$ days delivered vaginally in our study. Out of the caesarean section group, 27 (48.2\%) patients had an emergency surgery. 29 (51.8\%) patients had an elective caesarean section.

Intraoperatively B lynch suturing was required in $3.5 \%$ of the total cases. And uterine artery ligation was needed in $7.1 \%$ of the total cases. Internal artery ligation was required in 1 patient $(1.78 \%)$ of the total cases.

Obstetric hysterectomy was required in 2 cases of placenta accreta at time of caesarean section which accounted to $3.5 \%$ of total cases and $100 \%$ for placenta accreta cases.

Re - laparotomy followed by hysterectomy for PPH was required in 1 case accounting to $1.78 \%$ of the total cases. These figures stress the need of senior obstetrician for cases of placenta previa. In our institute as a protocol we have a senior and a junior obstetrician consultant team dealing with placenta previa cases. For cases of placenta accreta prior presence of urologist is sought. The benefits of team approach in placenta previa and placenta accreta have been studied in one earlier study by Kassem G, Alzahrani A. ${ }^{18}$

Out of 7 cases which required devascularisation surgical consultant had to be called in one case for internal iliac ligation.

There was no case of bladder, ureteric or bowel injury in our study. Cases of bladder involvement in placenta accreta and need of a urologist have been reported in literature. $^{19}$

Blood and blood components were required in 53.5\% patients. Requirement of PRBCs ranged from 1-5 units. $3.57 \%$ patients required transfusion of FFPs. $46.4 \%$ patients did not require blood and had a good maternal outcome. Studies have shown that placenta previa carries greater risks of surgical complications including obstetric hysterectomy and significant risk of bleeding thus requiring blood transfusion. ${ }^{9,20}$ So round the clock availability of blood and blood components is mandatory in centres dealing with these cases.

\section{1\% patients needed ICU care after delivery.}

No case of post-operative sepsis, DIC, renal failure occurred in the study period. ICU stay in shifted patients ranged from 1-3 days only. No case of nosocomial infection was found.

Fortunately, there was no maternal mortality in the study group. In a study conducted by A.G Eller benefits of multidisciplinary care for women with suspected placenta accreta have been evaluated They found that women 
managed by a multidisciplinary team were less likely to experience composite early morbidity (prolonged maternal admission to the intensive care unit, largevolume blood transfusion, coagulopathy, ureteral injury, or early reoperation) than women managed standard obstetric care. $^{21}$

The mean gestational age at delivery was $35 \pm 2.4$ weeks ranging from $27.5 \mathrm{wks}$ - $39 \mathrm{wks}$. Prematurity as a neonatal complication has been reported in earlier studies also. ${ }^{11-14}$ According to RCOG guidelines elective delivery by caesarean section in asymptomatic women is not recommended before 38 weeks of gestation for placenta previa or before $36-37$ weeks for placenta accreta. ${ }^{17}$

No significant association between the APGAR score and type of placenta previa was found in our study. One earlier study has reported lower mean APGAR score in neonates of mothers with incomplete placenta previa when compared with complete placenta previa. ${ }^{22}$ Two neonates in our study could not be revived. Adverse perinatal outcome in placenta previa have been reported in earlier studies. ${ }^{11,12}$

One case in study needs special mention. Patient was diagnosed on USG as type II placenta previa and presented with on and off spotting per vaginum. On per speculum examination, bleeding was found to be from a cervical polyp. Polypectomy was done at 32 weeks of gestation under anaesthesia and later on patient underwent caesarean section after 4 weeks. This case highlights the importance of doing per speculum examination in all cases of APH diagnosed as placenta previa on USG.

This hospital based retrospective study was conducted in a tertiary level setting in Amritsar and thus conclusions cannot be generalized. The facility for uterine artery embolization is lacking in our institution presently. However, the following recommendations can be considered.

1. Antenatal registration should be done for all pregnant women.

2. Patients who are diagnosed with low lying placenta; in mid trimester should be informed about the various complications associated with placenta previa. Patients and attendants should be sensitized about the need of delivery at a tertiary care centre.

3. All women should be prepared for any emergency situations; the emphasis being on anemia correction and management of comorbid conditions.

4. In cases with previous history of caesarean section and curettage placental localization should be specially looked for.

5. Prior alerts as availability of transport, infrastructure, blood bank facility, expertise go a long way in saving lives of mother.
6. Training of obstetrician in stepwise devascularisation and peripartum hysterectomy is must with increasing rates of caesarean section.

\section{Audit parameters}

The discussion centres around following:

1. Maternal morbidity - severity and type if any is to be reduced

2. Maternal mortality- targeted to minimal zero in placenta previa

3. Neonatal morbidity and mortality - risk reduction and improvisation required

4. Infrastructure and facility provision - all interventions are available except uterine artery embolization. The provisions for the modalities are sought after.

Funding: No funding sources

Conflict of interest: None declared

Ethical approval: The study was approved by the Institutional Ethics Committee

\section{REFERENCES}

1. Reveiz L, Gyte GM, Cuervo LG. Treatments for iron-deficiencyanaemia in pregnancy. Cochrane Database Syst Rev. 2007;4:CD003094.

2. Cunningham F, Williams J. Williamsobstetrícia. $24^{\text {th }}$ Ed. México, McGraw-Hill Education; 2014:801.

3. Ananth C. Effect of Maternal Age and Parity on the Risk of Uteroplacental Bleeding Disorders in Pregnancy. Obstet Gynecol. 1996;88(4):511-6.

4. Ananth C, Smulian J, Vintzileos A. The association of placenta previa with history of cesarean delivery and abortion: A meta-analysis. Am J Obstet Gynecol. 1997;176(1):S144.

5. Gilliam M, Rosenberg D, Davis F. The Likelihood of Placenta Previa With Greater Number of Cesarean Deliveries and Higher Parity. Obstet Gynecol. 2002;99(6):976-80.

6. Monica G, Lilja C. Placenta previa, maternal smoking and recurrence risk. Acta Obstetriciaet Gynecologica Scandinavica. 1995;74(5):341-5.

7. Macones GA, Sehdev HM, Parry S, Morgan MA, Berlin JA. The association between maternal cocaine use and placenta previa. Am J Obstet Gynecol. 1997; 177:1097-100.

8. Sample registration system, Maternal mortality in india: 1997-2003, Trends, causes and risk factors. New Delhi: Registrar General of India, New Delhi(in collaboration with center for Global Health Research, University of Toronto, Canada); 2006.

9. Rouse DJ, MacPherson C, Landon M, Varner MW, Leveno KJ, Moawad AH, et al. Blood transfusion and cesarean delivery. Obstet Gynecol. 2006;108(4):891-97.

10. Gielchinsky Y, Rojansky N, Fasouliotis SJ, Ezra Y. Placenta accreta- summary of 10 years: a survey of 310 cases. Placenta. 2002;23:210-4. 
11. Ananth CV, Smulian JC, Vintzileos AM. The effect of placentapraevia on neonatal mortality: a population-based study in the United States, 1989 through 1997. Am J Obstet Gynecol. 2003;188:12993.

12. Zlatnik M, Cheng Y, Norton M, Thiet M, Caughey A. Placenta previa and the risk of preterm delivery. J Matern Neonatal Med. 2007;20:719-23.

13. Faiz A, Ananth C. Etiology and risk factors for placenta previa: an overview and meta-analysis of observational studies. J Maternal-Fetal Neonatal Medicine. 2003;13(3):175-90.

14. Sekiguchi A, Nakai A, Kawabata I, Hayashi M, Takeshita T. Type and location of placenta previa affect preterm delivery risk related to antepartum hemorrhage. Int J Med Sci. 2013;10(12):1683-8.

15. Erez O, Novack L, Klaitman V, Erez-Weiss I, BeerWeisel R, Dukler D et al. Early preterm delivery due to placenta previa is an independent risk factor for a subsequent spontaneous preterm birth. BMC Pregnancy and Childbirth. 2012;12(1):82.

16. Singh PM, Rodrigues C, Gupta A. Placenta previa and previous cesarean section. Obstetric Gynecologic Survey. 1982;37(4):245.

17. IJRCOG, placenta praevia, placenta praevia accreta and vasa praevia: diagnosis and management GreenTop Guideline; 2011.
18. Kassem G, Alzahrani A. Maternal and neonatal outcomes of placenta previa and placenta accreta: three years of experience with a two-consultant approach. Int J Women's Health. 2013;5:803-10.

19. Konijeti, Ramdev, Rajfer J, Askari A. Placenta percreta and the urologist. Rev Urol. 2009;11(3):1736.

20. Wortman AC, Twickler DM, McIntire DD, Dashe JS. Bleeding complications in pregnancies with lowlying placenta. J Matern Fetal Neonatal Med. 2016;29(9):1367-71.

21. Eller AG, Bennett MA, Sharshiner M, Masheter C, Soisson AP, Dodson M et al. Maternal morbidity in cases of placenta accreta managed by a multidisciplinary care team compared with standard obstetric care. Obstet Gynecol. 2011;117(2 Pt 1):331-7.

22. Daskalakis G, Simou M, Zacharakis D, Detorakis S, Akrivos N, Papantoniou $\mathrm{N}$ et al. Impact of placenta previa on obstetric outcome. Int J Gynaecol Obstet. 2011;114(3):238-41.

Cite this article as: Sood R, Sharma S, Nagpal M, Arora M. Current placenta previa management and outcome in a rural tertiary care centre. Int J Reprod Contracept Obstet Gynecol 2017;6:2050-5. 